\title{
The efficacy of topical human amniotic membrane-mesenchymal stem cell-conditioned medium (hAMMSC-CM) and a mixture of topical hAMMSC-CM + vitamin C and hAMMSC-CM + vitamin $\mathrm{E}$ on chronic plantar ulcers in leprosy: $\mathrm{A}$ randomized control trial
}

CRS Prakoeswa, FR Natallya, D Harnindya, A Thohiroh, RN Oktaviyanti, KD Pratiwi, MA Rubianti, B Yogatri, PI Primasari, N Herwanto, MD Alinda, BH Kusumaputra, L Astari, MY Listiawan, I Agusni \& FA Rantam

To cite this article: CRS Prakoeswa, FR Natallya, D Harnindya, A Thohiroh, RN Oktaviyanti, KD Pratiwi, MA Rubianti, B Yogatri, PI Primasari, N Herwanto, MD Alinda, BH Kusumaputra, L Astari, MY Listiawan, I Agusni \& FA Rantam (2018): The efficacy of topical human amniotic membranemesenchymal stem cell-conditioned medium (hAMMSC-CM) and a mixture of topical hAMMSC$\mathrm{CM}+$ vitamin C and hAMMSC-CM + vitamin E on chronic plantar ulcers in leprosy: A randomized control trial, Journal of Dermatological Treatment, DOI: 10.1080/09546634.2018.1467541

To link to this article: https://doi.org/10.1080/09546634.2018.1467541

Accepted author version posted online: 19 Apr 2018. 
The efficacy of topical human amniotic membrane-mesenchymal stem cellconditioned medium (hAMMSC-CM) and a mixture of topical hAMMSC$\mathrm{CM}+$ vitamin $\mathrm{C}$ and hAMMSC-CM + vitamin $\mathrm{E}$ on chronic plantar ulcers in leprosy: A randomized control trial

CRS Prakoeswa ${ }^{1}$, FR Natallya ${ }^{1}$,D Harnindya ${ }^{1}$, A Thohiroh ${ }^{1}$, RN Oktaviyanti $^{1}{ }^{1}, \mathrm{KD}_{\text {Pratiwi }}{ }^{1}$, MA Rubianti ${ }^{1}$, B Yogatri ${ }^{1}$, PI Primasari ${ }^{1}$, N Herwanto ${ }^{1}$, MD Alinda $^{1}$, BH Kusumaputra, L Astari $^{1}$, MY Listiawan, I Agusni ${ }^{1}$, FA Rantam ${ }^{2,3}$

${ }^{1}$ Department of Dermatology-Venereology, Dr. Soetomo Teaching Hospita//School of Medicine, Universitas Airlangga, Surabaya, Indonesia

${ }^{2}$ Stem Cell Research and Development Center, Universitas Airlangga, Surabaya, Indonesia.

${ }^{3}$ Virology and Immunology Laboratory, Department of Microbiology, Faculty of Veterinary Medicine, Universitas Airlangga, Surabaya, Indonesia

\section{Corresponding author:}

\section{Cita Rosita Sigit Prakoeswa}

Address: Prof Dr Moestopo No. 47, Surabaya, East Java, Indonesia

Telephone: +62811328199

Fax number: +62315501609

Email address: drcita.rosita@gmail.com 
The efficacy of topical human amniotic membrane-mesenchymal stem cellconditioned medium (hAMMSC-CM) and a mixture of topical hAMMSCCM + vitamin C and hAMMSC-CM + vitamin E on chronic plantar ulcers in leprosy: A randomized control trial

\section{ABSTRACT}

Background: Healing of chronic plantar ulcers in leprosy (CPUL) typically takes a long time due to impaired neurological function, thereby reducing the levels of growth factors and cytokines. Cytokines can be found in metabolite products from amniotic membrane stem cells. Chronic ulcers are frequently characterized by high levels of reactive oxygen species. Vitamin E ( $\alpha$ tocopherol) is widely used in skin lesions, owing to its antioxidant and antiinflammatory properties. Vitamin $\mathrm{C}$ also has antioxidant, anti-inflammatory, and collagen synthesis properties useful in wound healing. Herein, we compared the effects of topical human amniotic membrane-mesenchymal stem cellconditioned medium (hAMMSC-CM) alone and with vitamins $\mathrm{C}$ and $\mathrm{E}$ on healing of CPUL.

Methods: In this randomized controlled trial, topical agents were applied every 3 days for up to 8 weeks. Ulcer size, side effects, and possible complications were monitored weekly.

Results: Healing percentage increased each week in all groups. Mean difference in ulcer size was the highest in the hAMMSC-CM+vitamin E group, implying better progress of wound healing. There were no side effects or complications. Conclusion: hAMMSC-CM+vitamin E is the best for healing of CPUL. 
Keywords: hAMMSC-CM, vitamin E, vitamin C, chronic plantar ulcers in leprosy

\section{Introduction}

Ulcers are defined as loss of continuity of skin tissue up to the dermis or deeper (subcutis). Approximately $30 \%$ of patients with leprosy have peripheral nerve damage, and $10 \%-20 \%$ of them have neuropathic ulcers due to peripheral nerve damage. Leprosy ulcers are present mostly in plantar pedis, particularly in areas with bony prominence. The plantar pedis is a part of the body that functions in walking; thus, the risk of experiencing trauma is greater in this area than in other body parts [1-3]. Healing of plantar ulcers in leprosy often is difficult and time-consuming due to decreasing levels of growth factors and cytokines as a result of a prolonged inflammatory condition. The inflammatory condition can be caused by infection and ischemia due to persistent pressure on the wound from disruption of nerve functions. This causes obstruction of the wound healing process and formation of a chronic ulcer [4-8].

Since the early 20th century, amniotic membranes have been used to treat widespread injuries, burns, chronic and deep ulcers, and surgical wounds that are difficult to close. Studies on amniotic membrane stem cells for repair and regeneration of cells have shown good results. The production of growth factors and cytokines, which are required for tissue healing, is one of the mechanisms of stem cells in the tissue healing process. Growth factors and cytokines can be found in the tissue medium of stem cells in in vitro conditions through its metabolite products, and thus they can be a useful modality in the process of cell regeneration [9-14]. 
Previous research has proven that injuries that are difficult to heal in humans are associated with high levels of oxidative stress. Wounds or chronic ulcers often show increasing levels of reactive oxygen species (ROS) or free radicals that can delay the wound healing process and inhibit formation of granulation tissue and epithelialization. Free radicals are formed in response to tissue damage and subsequently inhibit the recovery process by attacking DNA, membranes, proteins, and lipids from cells. Antioxidants are believed to repair wounds by reducing damage caused by free radicals released by neutrophils in the inflammatory phase of wound healing [15-17].

Prakoeswa et al. [18] compared the effects of topical human amniotic membranemesenchymal stem cell-conditioned medium (hAMMSC-CM) and the framycetin gauze dressing (FGD) applied every 3 days for up to 8 weeks on healing of chronic plantar ulcers in leprosy (CPUL). Ulcer healing was significantly better in the hAMMSC-CM group than in the FGD group clinically and statistically $(p<0.005$ and $p<0.005)[18]$.

The role of vitamin C, a known antioxidant, in collagen synthesis has believed to be useful in wound healing. As an antioxidant, vitamin C neutralizes ROS found in chronic ulcers. Vitamin C also directly stimulates collagen synthesis. Sodium ascorbyl phosphate (SAP) is a stable derivative of vitamin C [19-21].

Vitamin E is a nonenzymatic, natural antioxidant and the most important lipid soluble in human tissue that is absorbed well by the skin. Several studies have shown that vitamin E, particularly $\alpha$-tocopherol, gives good results in the wound healing process. $\alpha$-Tocopherol may serve as an antioxidant, reducing ischemic damage due to reperfusion disorders, and may stimulate growth and stabilize granulation tissue, as well as re-epithelialization [23,24].

In light of the aforementioned facts, the present study investigated the effect of topical gel hAMMSC-CM only (group 1) and a mixture of hAMMSC-CM + vitamin C (group 2) and hAMMSC-CM + vitamin E (group 3) on healing of CPUL. 


\section{Material and methods}

\section{Study design and patients}

This experimental analytical randomized controlled clinical trial was performed using parallel designs in 22 subjects in each of the three treatment groups. Consecutive sampling was performed, i.e., we enrolled any patient with CPUL who met the criteria for admission samples at the Dermatology Venereology outpatient clinic,Dr Soetomo Teaching Hospital. The subjects were leprosy patients with CPUL of $>6$ weeks, an ulcer depth of $<0.5$ $\mathrm{cm}$, and a maximum injury area of $9 \mathrm{~cm}^{2}$ who did not consume systemic corticosteroids in the last 2 weeks. The subjects also had no history of diabetes mellitus, hemophilia, blood clotting physiological disorders, antiplatelet use, and hypersensitivity to transparent film dressings or adhesive plasters. This clinical study was approved by the ethical committee board of Dr. Soetomo Teaching Hospital Surabaya and was randomized with computerized and consecutive sampling.

\section{Treatment intervention}

Surgical debridement was performed in all groups before treatment to remove callus and necrotic tissue and return all ulcers to the same healing phase, i.e., the coagulation and inflammatory phase. The drug was applied every 3 days until the ulcer closed or for a maximum of 8 weeks. An extensive and deep ulcer measurement and evaluation of side effects and complications of both drugs were conducted weekly. Off-loading was not performed in any subject. Subjects were recommended only to reduce standing and walking activities.

\section{Laboratory testing}

Spectrophotometric examination was conducted using a spectrophotometer by measuring the absorbance at $280 \mathrm{~nm}$ to determine the total protein content per $\mathrm{mL}$ fluid of stem cell metabolite products and obtain the total protein content in hAMMSC-CM to be 
used at $5.05 \mathrm{mg} / \mathrm{mL}$. The hAMMSC-CM stability test was conducted in the laboratory testing unit of the Faculty of Pharmacy Universitas Airlangga for 4 weeks. The test was performed to determine the total protein content in hAMMSC-CM, which was $[1.38 \pm 0.1] \% \mathrm{w} / \mathrm{w}$ on day one and $[1.25 \pm 0.02] \% \mathrm{w} / \mathrm{w}$ on day $30 . \alpha$-Tocopherol and SAP stability tests also were performed to determine the levels of $\alpha$-tocopherol in groups 2 and 3. The $\alpha$-Tocopherol content was measured weekly using high performance liquid chromatography for 4 weeks. The $\alpha$-tocopherol and SAP contents were $[8.76 \% \pm 0.1] \% \mathrm{w} / \mathrm{w}$ on day 1 and $[9.55 \% \pm$ $0.1] \% \mathrm{w} / \mathrm{w}$ on day 30 . The total protein and $\alpha$-tocopherol contents of metabolites of stem cell products were relatively stable until week 4 , and thus the product mix metabolite in groups 2 and 3 could be regenerated every 4 weeks, which were applied to the ulcer once every 3 days for a maximum of 8 weeks or 14 applications.

\section{Statistical analysis}

All enrolled patients were evaluated. The nonparametric Mann-Whitney $U$ test was used to determine significant differences between samples before and after treatment within the same group and between two groups. $P<0.05$ indicated statistical significance. All statistical analyses were performed using SPSS version 22.0 software (SPSS, Inc., Chicago, IL, USA).

\section{Results}

The patients were divided almost equally between male and female sexes. The mean age of patients in all groups was $52.18 \pm 1.33$ years, mean ulcer duration was $1.41 \pm 0.36$ years, and mean ulcer size at baseline was $2.64 \pm 0.50 \mathrm{~cm}^{2}$ (Table 1). There were no dropouts in the study. All included patients completed the study protocol.

The mean percentage of ulcer healing per week in groups 2 and 3 is shown in Figure 1. The healing percentage increased each week in all groups. At the end of the study, mean reduction in ulcer size and depth was $1.70 \pm 1.05 \mathrm{~cm}^{2}$ and $0.35 \pm 0.14 \mathrm{~cm}^{2}, 2.01 \pm 1.19 \mathrm{~cm}^{2}$ 
and $0.25 \pm 0.11 \mathrm{~cm}^{2}$, and $2.84 \pm 1.67 \mathrm{~cm}^{2}$ and $0.27 \pm 0.15 \mathrm{~cm}^{2}$ in groups 1,2 , and 3 , respectively (Table 2).

The clinical improvement in the ulcers at the end of the study is shown in Table 3. The numbers of patients in whom ulcers were improved (ulcer size was smaller at the end of the study compared with that at baseline), persisted (ulcer size remained the same at the end of the study), and worsened (ulcer size was larger at the end of the study) are shown in Figure 2. In this study, the percentage of improved ulcers was higher in groups 2 and 3 (22\%) than in group $1(21 \%)$. Clinical picture before and after application of gel in each groups shown in Figure 3, 4, and 5, respectively.

No adverse events were encountered in any group. During clinical examination, no patient had any clinical signs of allergic contact dermatitis or infection (no erythema of the skin around the ulcer, no swelling, no warmth on palpation, no odor, and no exudation).

The difference in the ulcer size before and after treatment in the three groups was compared using the Mann-Whitney $U$ test. The results showed a significant difference among the three groups in ulcer size $(p<0.005)$ and depth $(p<0.005)$, with the best result occurring in group 3 .

\section{Discussion}

Table 1 shows that the work risk and duration of ulcer formation were not different among the groups. At the end of the study, good clinical outcomes were obtained in all groups: 21 ulcers (98.5\%) improved in group 1, 22 (100\%) improved in group 3 with no worsening ulcers, and $22(100 \%)$ improved in group 2. There was a trend for decreasing ulcer width and depth in groups 2 and 3 per week (Table 2). In the comparative test of the ulcer size among groups 1,2 , and 3 , the mean width was significantly different $(p=0.000 ; p$ $=0.000 ; p=0.000$, respectively), but there was no significant difference in mean depth from 
the beginning to the end of treatment. The results indicated that the mean weekly improvement in ulcer width up to the end of treatment was better in group 3 than in groups 1 and 2, whereas the mean depth improvement did not differ among the groups.

In dermatology, vitamin $\mathrm{C}$ is known as an antioxidant with a role in collagen synthesis. These functions are believed to be useful in wound healing. The antioxidant function of vitamin $\mathrm{C}$ is beneficial in neutralizing ROS present in chronic ulcers. Vitamin $\mathrm{C}$ also directly stimulates collagen synthesis. SAP is a stable derivative of vitamin C. Although this derivative has the same function as that of vitamin $\mathrm{C}$, it has better stability. The use of vitamin $\mathrm{C}$ and metabolite products simultaneously is expected to accelerate wound healing, with faster healing times, thereby resulting in less cost and increased quality of life of patients $[19,20,22,25-28]$.

To date, reports have discussed the effect of the mixture of hAMMSC-CM + vitamin E on the wound healing process, but some studies have been conducted to determine the effect of growth factors and vitamin E separately on wound healing; all studies have shown satisfactory results $[23,24]$.

A randomized controlled trial was conducted by Uchi et al. [9] to evaluate the efficacy of a topical fibroblast growth factor (bFGF) in 150 patients with chronic nonischemic diabetic ulcers. The subjects were divided into placebo $(n=51), 0.001 \% \mathrm{bFGF}$ $(n=49)$, and $0.01 \%$ bFGF $(n=49)$ groups and received treatment for a maximum of 8 weeks. At the end of the study, ulcers with a wound healing area of $>75 \%$ were found in $57.5 \%, 72.3 \%$, and $82.2 \%$ of the patients, respectively, with a significant difference found between the $0.01 \% \mathrm{bFGF}$ and placebo groups $(p=0.025)$ [9].

The results were in accordance with those of our study. The anti-inflammatory cytokines contained in the agents administered to groups 1 to 3 are thought to relieve tissue stress due to persistent pressure on the ulcers caused by work that requires much standing or 
walking. The levels of pro-inflammatory cytokines and increasing protease in chronic wounds cause the wound to remain in a prolonged inflammatory phase. A high protease enzyme will decrease the local growth factor production, and therefore, the wound will not enter the wound healing proliferation phase $[29,30]$.

A study analyzing the product of mesenchymal stem cell metabolites showed that many mediator substances, such as growth factors, cytokines, and chemokines, that are essential for tissue repair can be found in the tissue medium of mesenchymal stem cell metabolites, particularly vascular endothelial growth factor, platelet-derived growth factor, basic fibroblast growth factor, epidermal growth factor, keratinocyte growth factor, and transforming growth factor-fi (TGF-p). Applications of a topical metabolite stem cell product can overcome a prolonged inflammatory phase in chronic wounds because it contains antiinflammatory cytokines and growth factors; thus, the inflammatory phase can be resolved, and the wound can enter the healing proliferation and remodeling phase $[12,13]$.

Fiori et al. [10] compared the rate of ulcer healing in the fingers of patients with systemic sclerosis. One group received standard ulcer treatment plus vitamin E gel application, and one group only received standard care procedures. The healing time and resolution of pain were faster in the group receiving vitamin E gel compared with those in the control group $(p<0.0001)$ [10]. Chronic ulcers showed increasing levels of ROS or free radicals, which could delay the wound healing process and inhibit formation of granulation tissue and epithelialization. Vitamin $\mathrm{E}$ is an antioxidant that can reduce damage caused by free radicals released by neutrophils in the inflammatory phase of the wound healing process $[3,5]$. In addition to its antioxidant activity, vitamin $\mathrm{E}$ has anti-inflammatory and antiaggregating properties and can cause vasodilation of small blood vessels. The level of vitamin E ( $\alpha$-tocopherol) in hAMMSC-CM + vitamin E gel is thought to reduce free radicals, reduce ischemic damage from reperfusion disorders, and stimulate growth and stabilization of 
granulation and re-epithelialization tissue that assisted in the ulcer healing process in this study [24].

Table 2 shows the comparison of ulcer size before and after overall treatment in each group. There was a significant decrease in the ulcer width and depth: $1.70 \pm 1.05 \mathrm{~cm}^{2}, p=0.000$ in group $1,2.84 \pm 1.67 \mathrm{~cm}^{2}, p=0.000$ in group 3 , and $2.01 \pm 1.19 \mathrm{~cm}^{2}, p=0.000$ in group 2 .

Reduced volume or depth of a wound was demonstrated by the proliferation of granulation tissue. Wound contraction was caused by granulation of the fibroblast/myofibroblast at the base of the wound. The degree of contraction and reepithelialization in the chronic wound healing process was highly dependent on the anatomic location and was not associated with the cause. Ligament retainers in loose tissue, such as the back, abdomen, or face, were more loose and rarer; thus, wound contraction had a major role in the healing process. Tightly adherent tissue, such as that in the palms, soles of the feet, or anterior tibial region, has a dense and firm skin ligament, and therefore the process of wound contraction was less important. The wound healing process in these areas was more dependent on epithelialization. An ulcer on the plantar pedis has a larger surface epithelial area to be closed by re-epithelialization compared with the depth of the ulcer through formation of granulation tissue. This was because the wound on the sole of the foot did not contract, and thus there was only a small amount of granulation tissue underlying the ulcer surface. This caused no significant difference in the mean ulcer depth before and after treatment among all groups [26,27].

The present study has a few limitations. We did not conduct off-loading, i.e., reducing or removing the load on the legs. Off-loading can be conducted via bed rest or via the use of crutches, wheelchairs, walkers, and special footwear [16]. The pressure on the plantar pedis in people with neuropathy should be distributed evenly to avoid high pressure in certain areas that may interfere with or inhibit healing of plantar ulcers. Subjects were recommended only 
to reduce standing or walking activities, but this was very difficult to implement because most subjects had to work to fulfill their daily needs. Another limitation was that there was no subject grouping based on the location of the ulcer and anatomical structure. Because ulcer healing is influenced by the amount of pressure obtained during standing and walking, the location of the ulcer and its anatomical structure has an important role. Ulcers located on the protrusion of the bone (the soles of the front legs, the soles of the hind legs) experience higher pressure than those on the middle palm when standing or walking.

\section{Conclusion}

The hAMMSC-CM + vitamin E gel clinically and statistically decreased the mean ulcer width more significantly than hAMMSC-CM only and hAMMSC-CM + vitamin C, but there was no difference in the mean ulcer depth in all groups. All gels have been proven to decrease the size of chronic plantar of leprosy ulcers by increasing the mean healing of the ulcer width and depth every week until week 8 , but the process was larger and faster in group

3. There were no complications or side effects due to gels in any subject. Further experimental analytic research in randomized controlled clinical trials should be conducted to compare effects of the gel on healing of CPUL with off-loading in the form of a foot board specifically designed to help reduce stress and repetitive mechanical stress, which can affect the healing process. In addition, further studies should apply additional criteria in selecting a good match between the groups (matching) according to the location of the ulcer and anatomical structure to reduce bias. 


\section{References}

1. Srinivasan H. Management of ulcers in neurologically impaired feet in leprosy affected persons. Surgical Reconstruction and Rehabilitation in Leprosy and other Neuropathies. 2004;15:193-226.

2. Dzikrina AM, Purnami SW. Modeling leprosy prevalence rate and the factors that influence in East Java with the approach of geographically weighted regression (GWR). Journal of Science and Arts POMITS 2013; 2 (2): 2337-3520.

3. Robson M. The role of growth factors in the healing of wounds chronics. Wound Repair and Regen 1997; 5 (1): 12-7.

4. Guo S, DiPietro LA. Factors Affecting Wound Healing, S. J Dent Res 2010; 89(3): 219-29.

5. Suryanarayan S, Budamakuntia L, Khadri SIS, Sarvajnamurthy S. Efficacy of autologous platelet- rich plasma in the treatment of chronic nonhealing leg ulcers. Plast aesthet Res 2014; 1 (2): 65-9.

6. Skardal A, Mack D, E Kapetanovic, Atala A, Jackson JD, Yoo J, et al. Bioprinted amniotic fluid- derived stem cells large Accelerate healing of skin wounds. Stem Cells transl Med 2012: 1: 792802.

7. Hendrijantini N, Kresnoadi U, Salim S, Agustono B, Retnowati E, Syahrial I, et al. Study biocompatibility and osteogenic differentiation potential of human umbilical cord mesenchymal stem cells (hucmscs) with gelatin solvent. J. Biomedical Science and Engineering. 2015;8:420-8.

8. Hatano K. Prevention and management of impairments and disabilities. In: Makino M, Matsuoka M, Goto M, Hatano K, editors. Leprosy-Science working towards dignity. 1st ed. Kanagawa: Tokai University Press; 2011. p.174-85. 
9. Rennie K, Gruslin A, Hengstschlager M, Pei D, Cai J, Nikaido T, et al. Application of amniotic membrane and fluid in stem cell biology and regenerative medicine. Stem Cells Int 2012: 1-13.

10. P Jayaraman, Nathan P, Vasanthan P, Moses S, V. Govindasamy stem cell conditioned medium: a new approach to skin wound healing management. Cell Bio Int 2013: 37: $1122-8$.

11. Falanga V, Iwamoto Satori. Mechanisms of wound repair, wound healing, and wound dressing. In: Goldsmith LA, Katz SI, Gilchrest BA, Paller AS, Leffell DJ, Wolff K, editors. Fitzpatrick's Dermatology in General Medicine, 8th edition. New York: The McGraw-Hill Companies; 2008. p. 2984-96.

12. Diaz-Prado S, Lopez EM, Gomez TH, Vazquez ER, Boquete IF, de Toro FJ, et all. Isolation and characterization of mesenchymal stem cells from human amniotic membrane. Tissue Eng Part C Methods. 2011;17:49-59.

13. Ennis WJ, Sui A, Bartholomew A. Stem Cells and Healing: Impact on Inflammation. Adv Wound Care 2013;7: 369-78.

14. Gregory C, Gunn W, Peister A, and Prockop D. An Alizarin Red-Based Assay of Mineralization by Adherent Cells in Culture: Comparison with Cetylpyridinium Chloride Extraction. Analytical Biochemistry. 2005;329:77-84.

15. Havlik RJ. Vitamin E and wound healing. Plastic surgery educational committee the data foundation. Plast Reconstr Surg 1997; 100: 1901-2.

16. Kouroupis D, Churchman S, English A, Emery P, and Giannoudis P. Assessment of Umbilical Cord Tissue as a Source of Mesenchymal Stem Cell/Endothelial Cell Mixtures for Bone Regeneration. Regenerative Medicine. 2013;8:569-81. 
17. Barreto JG, Salgado CG. Clinic-epidemiological evaluation of ulcers in patients with leprosy sequelae and the effect of low level laser therapy on wound healing: a randomized clinical trial. BMC Infect Dis. 2010;237(10):1-9.

18. Prakoeswa CRS. Efficacy of topical human amniotic membrane mesenchymal stem cell-conditioned medium (hAMMSC-CM) on the healing of chronic plantar ulcers in leprosy: a controlled prospective clinical trial (in press)

19. Telang PS. Vitamin C in dermatology. Indian Dermatol Online J. 2013; 4: 143-6.

20. Moro O. Biological activities of stable ascorbic acid derivative, 2-0-a-Dglucopyrasonyl-L-ascorbic acid (AA-2G) in cosmetics.Shiseido Research Center. J ApplCosmetol 1999;18: 154-63.

21. Telang PS. Vitamin C in dermatology. Indian Dermatol Online J. 2013; 4: 143-6.

22. Moro O. Biological activities of stable ascorbic acid derivative, 2-0-a-Dglucopyrasonyl-L-ascorbic acid (AA-2G) in cosmetics.Shiseido Research Center. J ApplCosmetol 1999;18: 154-63.

23. Thiele J, Ekanayake-Mudiyanselage S. Vitamin E in human skin: organ-specific physiology and consideration for its use in dermatology. Mol Aspects Med 2007; 28: 646-6. 24. Fiori G, Galluccio F, F Braschi, Amanzi L, Miniati I, Conforti ML et al. Vitamin E gel Reduces the time of healing of digital ulcers in systemic sclerosis. Clin Exp Rheumatol 2009; 27: 51-4.

25. Maxson S, Lopez EA, Yoo Fund, Miagkova ADK, Leroux M. Concise review: the role of mesenchymal stem cells in wound repair. Stem Cells transl Med 2012; 1: 142-9.

26. Levinson H. A Paradigm of Fibroblast Activation and Dermal Wound Contraction to Guide the Development of Therapies for Chronic Wounds and Pathologic Scars. Adv Wound Care (New Rochelle), 2013; 2: 149-159. 
27. Wu SC, Crews RT, Armstrong DG. The pivotal role of offloading in the management of neuropathic foot ulceration. Curr Diab Rep 2005; 5 (6): 423.

28. Singh P, Singh P. Role of Topical Ascorbic Acid in Management of Refractory Corneal Ulcer. IOSR Journal of Pharmacy 2012; 2: 1-4

29. Sarpooshi HM, Vaheb M, Tabarayee Y, Sabzevar AV, Mortazavi F.The effects of topical vitamin $\mathrm{C}$ solution on the necrotic tissue volume of burn wounds. Journal of Nursing and Midwifery Sciences 2016: 3(3): 11-17.

30. Fite A, Dykhuizen R, Litterick A, Golden M,Leifert C. Effects of Ascorbic acid, gluthathione, thiocyanate, and iodide on antimicrobial activity of acidified nitrite. Antimicrob Agents Chemother 2004;48:655-65. 
Table 1. Demographics of the patients and baseline characteristics

Variable

$\begin{array}{lll}\text { Group 1 } & \text { Group 2 } & \text { Group 3 } \\ (n=22) & (n=22) & (n=22)\end{array}$

Sex

- Male, $n(\%)$

$13(59.1) \quad 9(40.9) \quad 8(63.6)$

- Female, $n(\%)$

$9(40.9)$

$13(59.1)$

$14(36.4)$

Age (years)

- 21-50 years, $n(\%)$

$12(54.5) \quad 12(54.5) \quad 10(45.4)$

- >50 years, $n(\%)$

$10(45.5) \quad 10(45.5) \quad 12(54.6)$

Occupation

- Requires long standing/walking, $n(\%)$

$11(50.0) \quad 10(45.5) \quad 10(45.5)$

- Does not require long standing/walking, $n(\%) \quad 11(50.0) \quad 12(54.5) \quad 12(54.5)$

Duration of ulcer (years)

- <1 year, $n(\%)$

$6(27.3) \quad 7(31.8) \quad 9(40.9)$

- 1-5 years, $n(\%)$

$15(63.6) \quad 15(68.2) \quad 13(59.1)$

- $>5$ years, $n(\%)$

$1(9.1)$

$0(0)$

$0(0)$ 
Table 2. Percentage of reduction of ulcers

$$
\text { Group } 1(n=22) \quad \text { Group } 2 \text { C }(n=22) \quad \text { Group } 3(n=22)
$$

The mean size of the ulcer \pm

SD

- Week I \pm SD

$0.69 \pm 0.47$

$0.32 \pm 0.47$

$0.47 \pm 0.59$

- $\quad$ Week II \pm SD

$1.08 \pm 0.59$

$0.79 \pm 0.63$

$1.01 \pm 0.69$

- $\quad$ Week III \pm SD

$1.31 \pm 0.74$

$1.18 \pm 0.75$

$1.67 \pm 1.35$

- $\quad$ Week IV \pm SD

$1.48 \pm 0.86$

$1.44 \pm 0.92$

$2.19 \pm 1.52$

- Week V \pm SD

$1.59 \pm 0.94$

$1.65 \pm 0.95$

$2.48 \pm 1.59$

- Week VI \pm SD

$1.65 \pm 0.97$

$1.75 \pm 0.99$

$2.64 \pm 1.64$

- $\quad$ Week VII \pm SD

$1.68 \pm 1.03$

$1.88 \pm 1.04$

$2.73 \pm 1.67$

- $\quad$ Week VIII \pm SD

$1.70 \pm 1.05$

$2.01 \pm 1.19$

$2.84 \pm 1.67$

The mean depth of the ulcer

$\pm \mathrm{SD}$

- Week I \pm SD

$0.15 \pm 0.11$

$0.04 \pm 0.05$

$0.05 \pm 0.07$

- Week II \pm SD

$0.21 \pm 0.14$

$0.09 \pm 0.09$

$0.09 \pm 0.08$

- $\quad$ Week III \pm SD

$0.26 \pm 0.15$

$0.15 \pm 0.11$

$0.14 \pm 0.11$

- $\quad$ Week IV \pm SD

$0.30 \pm 0.16$

$0.19 \pm 0.10$

$0.18 \pm 0.13$

- Week V $\pm \mathrm{SD}$

$0.32 \pm 0.15$

$0.21 \pm 0.09$

$0.23 \pm 0.14$

- $\quad$ Week VI $\pm S D$

$0.33 \pm 0.15$

$0.24 \pm 0.11$

$0.25 \pm 0.14$

- Week VII \pm SD

$0.34 \pm 0.15$

$0.24 \pm 0.11$

$0.26 \pm 0.14$

- Week VIII \pm SD

$0.35 \pm 0.14$

$0.25 \pm 0.11$

$0.27 \pm 0.15$ 
Table 3. Clinical improvement of the ulcers at the end of the study Improvement of ulcers at the Group $1(n=22) \quad$ Group $2(n=22) \quad$ Group $3(n=$ end of the study

\begin{tabular}{lccc}
\hline Improved, $n(\%)$ & $21(95.5)$ & $22(100)$ & $22(100)$ \\
Persisted, $n(\%)$ & $1(4.5)$ & $0(0)$ & $0(0)$ \\
Worsened, $n(\%)$ & $0(0)$ & $0(0)$ & $0(0)$
\end{tabular}

Figure 1. The mean percentage of size reduction in ulcers every week in the three groups

hAMMSC-CM: human amniotic membrane-mesenchymal stem cell-conditioned medium

Figure 2. Clinical improvement of the ulcers at the end of the study

Figure 3. (A) Chronic ulcer before application in group 1. (B) Recovered ulcer at week 2 after gel application.

Figure 4. (C) Chronic ulcer before gel application in group 3. (D) Recovered ulcer at week 2 after gel application.

Figure 5. (E) Chronic ulcer before gel application in group 2. (F) Recovered ulcer at week 4 after gel application. 


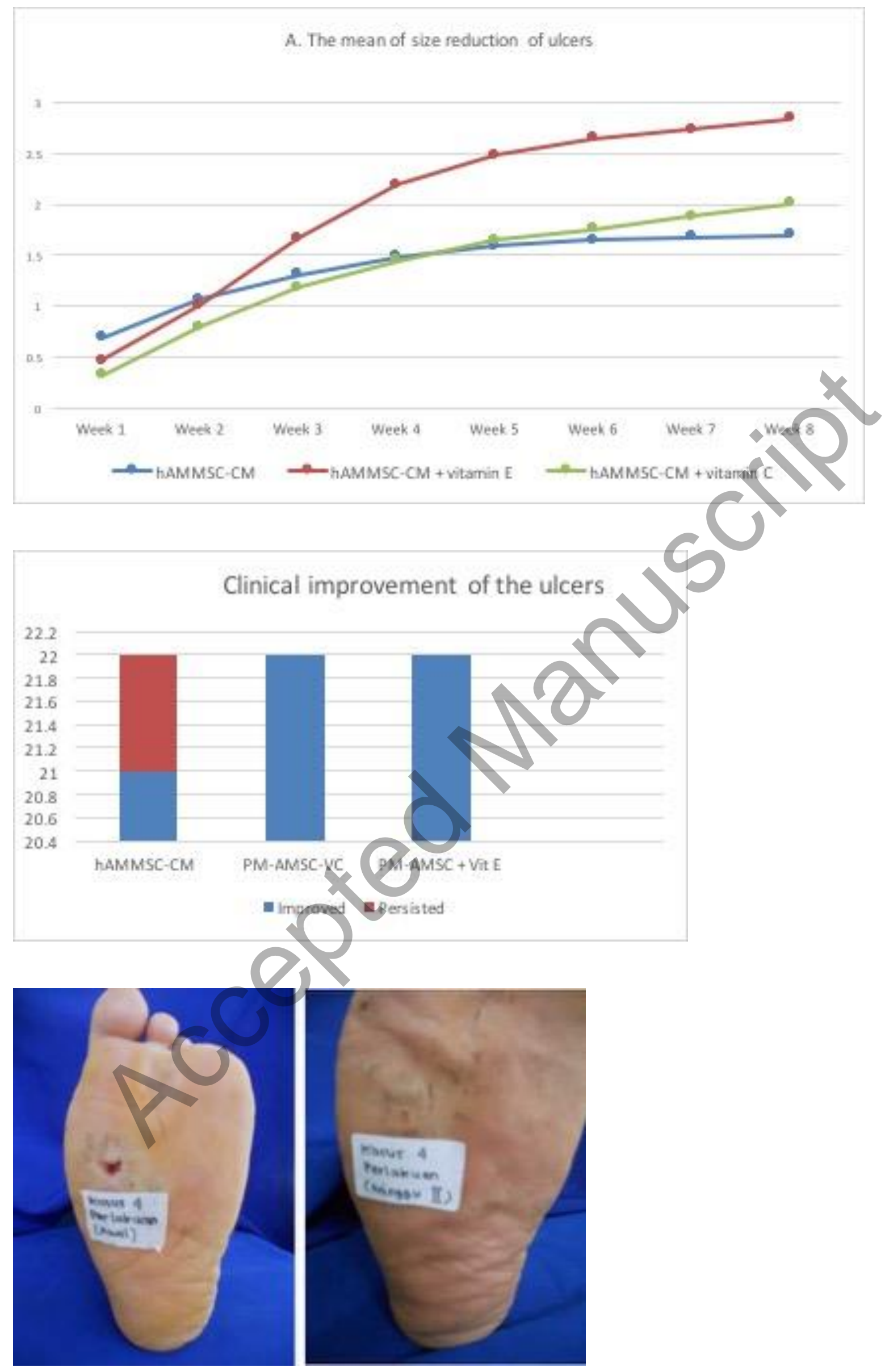



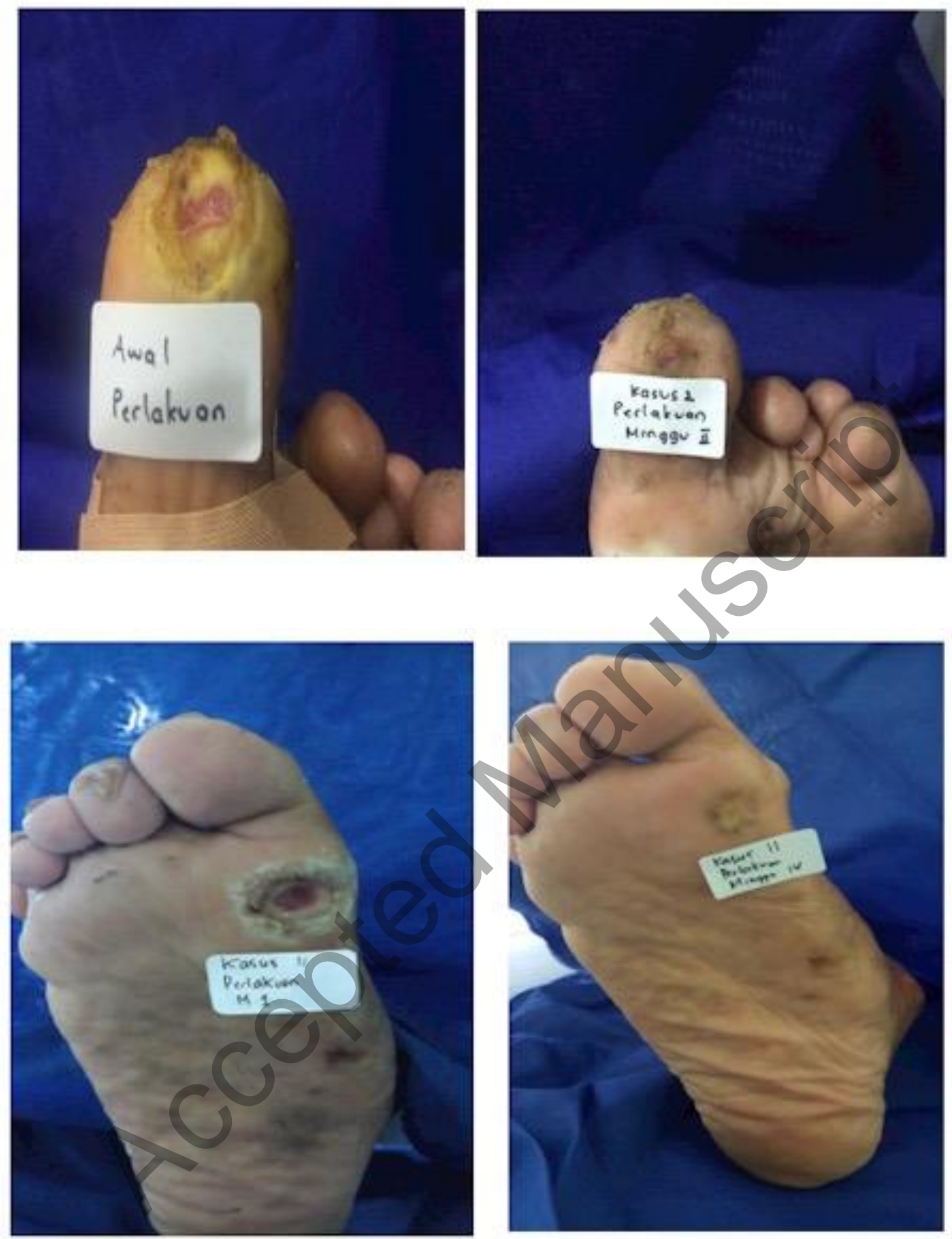